\title{
New Therapies for Advanced Thyroid Cancer
}

\author{
Diprajan Laha, Naris Nilubol and Myriem Boufraqech* \\ Surgical Oncology Program, National Cancer Institute, National Institutes of Health, Bethesda, MD, United States
}

Thyroid cancer is the most common endocrine cancer. The discovery of new biomarkers for thyroid cancer has significantly improved the understanding of the molecular pathogenesis of thyroid cancer, thus allowing more personalized treatments for patients with thyroid cancer. Most of the recently discovered targeted therapies inhibit the known oncogenic mechanisms in thyroid cancer initiation and progression such as MAPK pathway, PI3K/Akt-mTOR pathways, or VEGF. Despite the significant advances in molecular testing and the discoveries of new and promising therapeutics, effective treatments for advanced and metastatic, iodine-refractory thyroid cancer are still lacking. Here, we aim to summarize the current understanding of the genetic alterations and the dysregulated pathways in thyroid cancer and to discuss the most recent targeted therapies and immunotherapy for advanced thyroid cancer with a promising anti-tumor activity and clinical benefit.

\section{OPEN ACCESS}

Edited by:

Veronica Vella

University of Catania, Italy

Reviewed by:

Alessandro Antonelli,

University of Pisa, Italy

Dario Giuffrida,

Mediterranean Institute of Oncology

(IOM), Italy

*Correspondence:

Myriem Boufraqech

myriem.boufraqech@nih.gov

Specialty section

This article was submitted to Cancer Endocrinology,

a section of the journal

Frontiers in Endocrinology

Received: 10 September 2019

Accepted: 07 February 2020

Published: 22 May 2020

Citation:

Laha D, Nilubol N and Boufraqech M

(2020) New Therapies for Advanced

Thyroid Cancer.

Front. Endocrinol. 11:82.

doi: 10.3389/fendo.2020.00082
Keywords: thyroid cancer, targeted therapies, advanced thyroid cancer, RAI-refractory, immunotherapy

\section{INTRODUCTION}

Thyroid cancer is originating from follicular epithelial cells or parafollicular $\mathrm{C}$ cells. Follicular cellsderived thyroid cancers are classified into 4 histological types: papillary thyroid cancer (PTC 80 $85 \%$ ), follicular thyroid cancer (FTC 10-15\%), poorly-differentiated thyroid cancer (PDTC, $<2 \%$ ), and anaplastic thyroid cancer (ATC, $<2 \%$ ). PTC and FTC are well-differentiated thyroid cancers (WDTC) accounting for most of thyroid cancer cases. The genetic alterations associated with differentiated thyroid cancer include, but are not limited to, BRAF, RAS mutations, or RET/PTC rearrangements which leads to the activation of MAPK oncogenic pathway. The existence of welldifferentiated or poorly differentiated foci within an undifferentiated tumor suggests a progressive dedifferentiation process of WDTC that leads to ATC. BRAF $\mathrm{F}^{\mathrm{V} 600 \mathrm{E}}$ mutation and RAS mutations are detected in $23 \%$ and $20 \%$ of ATC, respectively, however additional co-occurrence of TP53 and TERT promoter mutations with known driver mutations are only common in ATC. These findings suggest that additional pathogenic alterations in tumor suppressors and oncogenes can lead to progression of WDTC to PDTC or ATC.

Surgical resection is the standard management for most patients with thyroid cancer. Patients with low-risk WDTC can be treated with surgery alone while those with high-risk features may require thyrotropin (TSH) suppression and radioiodine therapy (RAI) (1). Although anaplastic thyroid cancer (ATC) is the most aggressive histological subtype of thyroid cancer, most thyroid cancer-related deaths are due to the progression of radioactive-iodine refractory WDTCs. The poor survival of these patients with advanced thyroid cancer shows the lack of effective therapeutic strategies.

In this review, we summarized all the new therapeutic strategies that showed response in advanced thyroid cancer. 


\section{A-CLASSIFICATION OF THYROID CANCER}

\section{Papillary Thyroid Carcinoma}

PTC is the most common type of thyroid carcinoma of follicular cell origin and accounts for $80 \%$ of all WDTC. PTC is driven by activating mutations in $B R A F, R A S$, or RET/PTC rearrangements which activates thyroid cell abnormal proliferation. Initial management of WDTC includes surgical resection, radioactive iodine ablation (RAI) and thyroid-stimulating hormone (TSH) suppression. Although thyroid cancer has a good prognosis, 10$15 \%$ of patients with thyroid cancer have recurrent disease, and $5 \%$ will develop distant metastasis (lungs and bones) and cancer specific-death occurs in some cases.

Analysis of morphological and pathological features of PTC in association with the clinical outcome of patients with PTC has identified several variants of papillary thyroid cancer: 1 - classical variant of PTC (50-60\% of PTC cases), is a low-risk subtype with an excellent prognosis, 2- Tall-cell variant of PTC (5-11\% of all PTC cases) is more aggressive than CPTC with a higher risk of locoregional and distance metastasis, recurrence, and mortality rates (2, 3), 3- Follicular variant of PTC (FVPTC) (24$33 \%$ of PTC cases) are divided into invasive encapsulated FVPTC and non-invasive encapsulated FV-PTC, also known as noninvasive follicular thyroid neoplasm with papillary-like nuclear features (NIFTP). NIFTP are classified as non-cancerous lesions with favorable clinical behavior (4). Rare histologic variants of PTC include solid, diffuse sclerosing, columnar, trabecular, oncocytic, and hobnail. These variants are associated with high rates of metastasis and thyroid cancer-related mortality $(3,5)$ and thus, are sometimes categorized as poorly differentiated thyroid cancer (PDTC).

\section{Follicular Thyroid Carcinoma}

Follicular thyroid carcinoma (FTC) is the second most common thyroid cancer after papillary carcinoma. Follicular carcinoma is also well-differentiated thyroid cancer like PTC, with more aggressive behavior. It is about $10-30 \%$ of all well-differentiated thyroid cancer (6). Oncogenic drivers in FTC are primarily $R A S$ single nucleotide alterations (NRAS, HRAS, and KRAS) and $P A X 8 / P P A R \gamma$ rearrangements. RAS mutations and PAX8PPAR $\gamma$ are mutually exclusive. RAS mutations are found in up to $40-50 \%$ of FTC; PAX8PPAR $\gamma$ fusions are found in $30-40 \%$ of FTC cases $(7,8) . R A S$ mutations and PAX8PPAR $\gamma$ fusions are not found in cPTC but are common in FV-PTC. Molecular alterations, mutations, and/or gene copy number variations of the PI3K/Akt pathway have been identified in FTC. Genetic copy gain of PIK3CA has a high prevalence in FTC (24\%) (9). PTEN silencing by inactivating mutations or epigenetic changes also occur in some FTC cases $(10,11)$.

\section{Poorly Differentiated Thyroid Cancer}

PDTC is characterized by the absence of classic nuclear features of PTC, high mitotic activity, and tumor necrosis. Patients with PDTC often present vascular invasion lymph node metastasis, extrathyroidal extension, and sometimes distant metastases $(12,13)$.
Many cases of PDTC are found in patients who have a history of well-differentiated thyroid carcinoma. Sometimes, foci of WDTC coexist with PDTC, suggesting dedifferentiation of the initial tumor. PDTC has a higher mutations rate compared to WDTC. RAS and BRAF mutations are found in $20-50 \%$ and up to $35 \%$ of PDTC cases, respectively (14). Genetic alterations that characterize PDTC and are associated with tumor aggressiveness are TERT promoter (20-50\%) mutations and TP53 mutations (10-35\%) that co-occur with RAS and BRAF mutations $(15,16)$. Other genetic alterations have been reported in PDTC such as CTNNB1 and EIF1AX mutations and $A L K$ rearrangements $(15,17)$. Somatic copy number alterations are common in PDTC with a gain of chromosome 1q, and loss of chromosomes 1p, 13q, $15 \mathrm{q}$, and $22 \mathrm{q}(15)$.

\section{Anaplastic Thyroid Carcinoma}

Anaplastic thyroid cancer (ATC) is a rare form of thyroid cancer with an extremely aggressive tumor behavior and uniformly lethal. ATC represents $1.7 \%$ of all thyroid cancer cases (18). ATC has a rapid progression and $75 \%$ of the patients present distant metastasis often in the lungs, bones, and the brain (19). ATC has a poor prognosis and accounts for $20-50 \%$ of all deaths from thyroid cancer (20) with a median survival of 3-6 months. ATC is refractory to current conventional treatments with radioiodine ablation and chemotherapy. Therefore, there is an urgent need for novel therapies for ATC. The better understanding of the molecular pathogenesis of ATC has allowed the discovery of new therapeutic strategies. Twenty to fifty percent of undifferentiated tumors are associated with WDTC suggesting and acquisition of additional genetic alterations leading to cancer dedifferentiation and acquisition of more aggressive phenotype (21). BRAF (20-45\%), TP53 (up to 70\%), and RAS (20-40\%) mutations are the most frequent alterations in ATC (22). In addition, TERT promoter mutations have been associated with BRAF mutation and more aggressive tumors. Many additional alterations implicated in the aggressive behavior of ATC have been reported. These alterations involve EIF1AX, NF1, KMT, and genes in the PI3K/Akt pathway (15). ATC cells are positive for keratin, vimentin, and $\mathrm{N}$-cadherin but negative for thyroid transcription factor-1, thyroglobulin, and NIS.

\section{B- Treatment Modalities of Thyroid Cancer}

The treatment of patients with thyroid cancer is often multidisciplinary involving surgeons, endocrinologists, medical oncologists, and nuclear medicine radiologists. Surgery remains the initial treatment of choice in patients with resectable thyroid cancer. In patients with metastatic differentiated thyroid cancer, total thyroidectomy with or without compartmentoriented lymph node dissection is still recommended to facilitate the use of radioiodine therapy and to reduce locoregional morbidity from tumor invasion. The extent of the initial thyroidectomy in patients with low-risk, differentiated thyroid cancer (tumor size smaller than $4 \mathrm{~cm}$. without preoperative evidence of extrathyroidal invasion or detectable adenopathy) remains controversial as a thyroid lobectomy may provide a comparable outcome to a total thyroidectomy (1). If lymph node metastases are detected, compartment-oriented therapeutic 
lymph node dissection is recommended. Prophylactic central neck lymph node dissection should be performed in patients with high-risk features for nodal metastasis such as T3-T4 tumors (1).

\section{Radioactive lodine Ablation}

The post-surgical management includes the RAI ablation especially for patients with high risks for tumor recurrence, patients with metastatic disease, and patients with persistent or recurrent disease. The benefit of RAI has been demonstrated in patients with a high risk for recurrence (23). RAI decreases the risk of recurrence and disease-related mortality. However, RAI for low-risk patients is controversial as there are no convincing data demonstrating its effectiveness and clinical benefit. Patients who have an excellent response after surgery, defined as undetectable thyroglobulin, do not require RAI ablation (1). High level of serum TSH by thyroid hormone withdrawal or by the administration of recombinant TSH is required to increase the uptake of radioactive iodine (I-131) in the tumor tissue by reinducing the expression of the sodium iodine symporter (NIS) in follicular cells (24).

\section{TSH Suppression}

Thyroid hormone replacement after surgical resection is necessary to replace endogenous hormones and to inhibit tumor growth by maintaining low TSH level and thus reducing the risk of recurrence (25-27). The clinical benefit of TSH suppression depends on the aggressiveness of the tumor. Recent ATA guidelines recommend TSH suppression for patients with high risk (TSH goal: $<0.1 \mathrm{mIU} / \mathrm{L}$ ) and intermediated risk (TSH goal: $0.1-0.5 \mathrm{mIU} / \mathrm{L}$ ) thyroid cancer. However, no data are demonstrating the benefit of low serum TSH level in patients with low-risk tumors after thyroidectomy (28).

\section{Treatment of Advanced Thyroid Cancer}

Standard therapy with surgical resection and radioactive iodine ablation fails in about $10 \%$ of differentiated thyroid cancer and all ATC. Therefore, a multimodal therapeutic approach that includes standard therapy and cytotoxic chemotherapy has been used for patients with advanced thyroid cancer but showed very limited efficacy. The significant scientific advances in the molecular characterization of thyroid cancer raised the use of more targeted therapies for advanced cancers. such as tyrosine kinase inhibitors, anti-angiogenic drugs. Recently, several novel drugs that target cell proliferation, angiogenesis, apoptosis, immunosuppression, metabolomic reprogramming, and epigenetic changes have been tested.

Somatic mutations in thyroid cancer cells lead to the activation of the MAPK and PI3K/Akt pathways. In vitro and preclinical studies showed an anti-tumor effect of agents targeting these pathways. BRAF ${ }^{\mathrm{V} 600 \mathrm{E}}$ inhibitor, vemurafenib, and MEK inhibitor selumetinib, demonstrated a reduction of the phosphorylation of ERK, increased cell cycle arrest and inhibition of tumor growth and metastasis in cell lines and in vivo models with MAPK activation (29-32). The growing body of evidence demonstrating the involvement of PI3K/Akt in thyroid carcinogenesis and drug resistance led to the discovery of several agents targeting the key members of this cascade. Inhibitors such everolimus and Torin-2 repressed tumors growth and cancer progression in vivo (33-35). Multi-kinase inhibitors targeting highly expressed tyrosine kinases (TK) in thyroid cancer cells, demonstrated a promising anti-tumor activity in vitro and in vivo. Due to its high affinity to VEGFR and FGFR, lenvatinib showed a high anti-angiogenic effects in thyroid cancer mouse model (36).

In addition to targeted therapies, immunotherapy by targeting PD-/PDL-1 axis showed a reduction of tumor growth in several pre-clinical models of aggressive thyroid cancer. Furthermore, inhibition of PD-1/PDL-1 demonstrated synergistic effects with $\mathrm{BRAF}^{\mathrm{V} 600 \mathrm{E}}$ inhibitor (37-39). Recent advances made in the field of cancer cell metabolism using targeted and untargeted approaches have provided data demonstrating the role of the metabolic reprogramming in carcinogenesis. The metabolic reprogramming has also been associated with genetic alterations (40). The dependence of cancer cells on certain metabolic pathways opens new avenues for the targeting of the altered metabolic pathway in patients with thyroid cancer. However, no clinical trials of drugs targeting cancer metabolic reprogramming have been initiated in patients with thyroid cancer. The following paragraph will discuss the major therapeutics strategies that have been proposed for advanced thyroid cancer.

\section{TARGETED THERAPIES AGAINST MAPK PATHWAY}

Mitogen-Activated Protein Kinase (MAPK) pathways connect extracellular signals to the network that controls cell proliferation, motility, and cell death. Thyroid cancer often presents genetic alterations that activate the MAPK pathway. These mutations include point mutations in BRAF and RAS or RET/PTC translocations (41-45). These mutations have been widely studied as a new therapeutic target in advanced thyroid cancer.

Vemurafenib and dabrafenib are $\mathrm{BRAF}^{\mathrm{V} 600 \mathrm{E}}$ inhibitors that function as ATP-competitive inhibitors. Vemurafenib has a much higher selectivity for mutated BRAF compared to wild type BRAF (46). A multicenter, phase I study of vemurafenib, included three patients with $B R A F^{\mathrm{V} 600 \mathrm{E}}$ mutated RAI-refractory-metastatic thyroid cancer (47) (Table 1), treated with different doses of vemurafenib at $240-360 \mathrm{mg}$ twice daily, and later increased to $720 \mathrm{mg}$ twice a day. One patient had a partial response with a $31 \%$ reduction of the target lesion in the lungs, and the other two patients had stable disease ( 9 and $16 \%$ reduction of the target lesion). The progression-free interval (the time from the first day of treatment to the date of the first disease progression or date of death) for the three patients were 11.4, 11.7, and 13.2 months, and the overall survival was 15,21 , and at least 31.7 months. The adverse events were similar to those were reported in a phase I study of patients with metastatic melanoma.

Based on these observations, a non-randomized, multicentric phase 2 trial was initiated. Patients 18 years or older, with recurrent or metastatic RAI-refractory papillary thyroid cancer positive for $B R A F^{V 600 E}$ mutation, with the measurable disease according to RECIST criteria, and evidence of progression in 
TABLE 1 | A table summarizing the recent clinical trials with targeted therapies that showed clinical benefits.

\begin{tabular}{|c|c|c|c|c|c|}
\hline Drug/targeted therapy & Thyroid cancer & $\mathbf{N}$ & ORR & OS, DFS & References \\
\hline Vemurafenib & $\begin{array}{l}\text { RAl-refractory-metastatic thyroid } \\
\text { cancer with } B R A F^{\mathrm{V} 600 \mathrm{E}} \text { mutation }\end{array}$ & 3 & $\begin{array}{l}1 \text { patient had a } P R \text {, and } \\
\text { two patients had SD }\end{array}$ & $\begin{array}{l}\text { time to disease progression: } 11.4 \text {, } \\
11.7 \text {, and } 13.2 \text { mo } \\
\text { OS: } 15,21 \text {, and at least } 31.7 \text { mo }\end{array}$ & $(47)$ \\
\hline Vemurafenib & $\begin{array}{l}\text { recurrent or metastatic } \\
\text { RAI-refractory papillary thyroid } \\
\text { with } B R A F^{\mathrm{V} 600 \mathrm{E}} \text { mutation }\end{array}$ & 22 & $\begin{array}{l}38.5 \% \text { of the patients had } \\
\text { PR and } 35 \% \text { had stable } \\
\text { disease. } \\
27.3 \% \text { of the patients had } \\
\text { a PR and } 27.3 \% \text { had SD }\end{array}$ & $\begin{array}{l}\text { Prior VEGFR-inhibitor: median PFS: } \\
8.9 \text { mo Median OS: } 14.4 \text { mo }\end{array}$ & $(48)$ \\
\hline Dabrafenib & $\begin{array}{l}\text { metastatic or unresectable PTC } \\
\text { with } B R A F^{\mathrm{V} 600 \mathrm{E}} \text { mutation }\end{array}$ & 10 & $\begin{array}{l}20 \% \text { had a PR and } 40 \% \\
\text { had SD treatment }\end{array}$ & & (49) \\
\hline $\begin{array}{l}\text { Dabrafenib and } \\
\text { Trametinib }\end{array}$ & $\begin{array}{l}\text { BRAF }{ }^{V 600 E} \text {-mutated } \\
\text { undifferentiated thyroid cancer }\end{array}$ & 16 & $\begin{array}{l}\text { One patient (16\%) had a } \\
\mathrm{CR} \text { and } 10 \text { patients }(63 \%) \\
\text { had a PR }\end{array}$ & $\begin{array}{l}\text { 12-month estimates of PFS: } 79 \% \text {, } \\
\text { and OS: } 80 \% \text {, respectively. }\end{array}$ & $(50)$ \\
\hline Pazopanib and trametinib & $\begin{array}{l}\text { Advanced thyroid cancer RAI } \\
\text { refractory }\end{array}$ & 12 & $\begin{array}{l}50 \% \text { of the patients had } \\
\text { SD and } 33 \% \text { had a PR }\end{array}$ & $\begin{array}{l}\text { Median PFS: } 10.7 \text { mo } \\
\text { Median OS: } 29.3 \mathrm{mo}\end{array}$ & $(51)$ \\
\hline Selumetinib & RAl-refractory thyroid cancer & 32 & $\begin{array}{l}1 \text { patient }(3 \%) \text { had a } P R, \\
54 \% \text { had } S D\end{array}$ & $\begin{array}{l}\text { Median PFS: } 32 \text { weeks Median PFS } \\
\text { for patients with } B R A F^{\mathrm{V} 600 \mathrm{E}}: 33 \\
\text { weeks vs } 11 \text { weeks for patients with } \\
\text { WT BRAF }\end{array}$ & $(52)$ \\
\hline Selumetinib & metastatic thyroid cancer & 20 & $\begin{array}{l}\text { Of the } 8 \text { patients treated } \\
\text { with radioiodine, } 5 \text { had PR } \\
\text { and and } 3 \text { had SD }\end{array}$ & & (53) \\
\hline everolimus & RAl-refractory thyroid cancer & $\begin{array}{l}33 \text { (DTC) } \\
7 \text { (ATC) }\end{array}$ & $\begin{array}{l}1 \text { patient }(3 \%) \text { had PR and } \\
27 \text { patients }(82 \%) \text { had SD } \\
\text { one patient }(14.2 \%) \text { had } \\
\text { near-CR and one patient } \\
(14.2 \%) \text { had SD }\end{array}$ & $\begin{array}{l}\text { Median PFS was } 12.9 \text { months } \\
\text { Median OS was not reached }\end{array}$ & $(54)$ \\
\hline everolimus & advanced thyroid cancer & 28 & $\begin{array}{l}17 \text { patients }(65 \%) \text { showed } \\
\text { SD }\end{array}$ & $\begin{array}{l}\text { Median PFS: } 9 \text { mo } \\
\text { Median OS: } 18 \mathrm{mo}\end{array}$ & $(55)$ \\
\hline Sorafenib & $\begin{array}{l}\text { advanced or metastatic thyroid } \\
\text { cancer }\end{array}$ & 207 & $\begin{array}{l}12.2 \% \text { of the patients had } \\
\text { PR }\end{array}$ & $\begin{array}{l}\text { Median PFS: } 20.5 \text { mo for } \\
B R A F^{\mathrm{V} 600 E_{-S}} \text { Sorafenib group vs } 8.9 \\
\text { months BRAFWT-sorafenib group } \\
\text { and } 5.5 \text { months for mutated } \\
\text { RAS-sorafenib group vs } 10.8 \\
\text { months for wild-type RAS-sorafenib } \\
\text { group) }\end{array}$ & $(56)$ \\
\hline Lenvatinib & $\begin{array}{l}\text { patients with RAl-refractory } \\
\text { differentiated thyroid cancer }\end{array}$ & 58 & $\begin{array}{l}50 \% \text { of the patients had } \\
\text { PR } \\
43 \% \text { of the patients had } \\
\text { SD and } 28 \% \text { had a } \\
\text { durable SD. }\end{array}$ & $\begin{array}{l}\text { median PFS was } 12.6 \text { mo } \\
\text { median OS could not be estimated }\end{array}$ & $(57)$ \\
\hline Lenvatinib & $\begin{array}{l}\text { RAI-refractory progressive } \\
\text { thyroid cancer }\end{array}$ & 261 & $\begin{array}{l}4 \text { patients }(1.5 \%) \text { had } \mathrm{CR} \\
165 \text { patients }(63.2 \%) \\
\text { had PR }\end{array}$ & Median PFS: 18.3 mo & (58) \\
\hline
\end{tabular}

the last 14 months was included. Patients who have previously been treated with BRAF or MEK inhibitors were excluded. The enrolled patients were divided into two groups, cohort 1; with patients who had never received a multikinase inhibitor targeting VEGFR and cohort 2 with participants who had been treated previously with a VEGFR inhibitor. All patients received vemurafenib $960 \mathrm{mg}$ twice a day (48) (Table 1). 38.5\% of the 26 patients who had never been treated with the anti-VEGFR inhibitor, showed a partial response and $35 \%$ of the participants had stable disease. In this cohort, the median duration of response was 16.5 months, and median PFS was 18.2 months. In the cohort of 22 patients who had received VEGFR-inhibitor, $27.3 \%$ showed partial response and $27.3 \%$ had stable disease for at least 6 months. For this cohort, the median duration of response was 7.4 months, median PFS was 8.9 months and median OS was 14.4 months. Fifty-five percent of the patients died after a median follow up of 12 months. Patients who have never received anti-angiogenic multikinase inhibitor showed a longer progression-free survival compared to patients who received vemurafenib as a second line of treatment. Approximately two-thirds of patients developed grade 3 and grade 4 adverse events. Dose reduction was required in $48-58 \%$ of patients. Twenty-seven percent of patients in TKI-naïve cohort required discontinuation of vemurafenib due to adverse events. Twenty percent of patients who were treated previously with multikinase inhibitors developed cutaneous squamous cell carcinoma, 8\% 
of patients in cohort 2 had cerebrovascular accident, and $8 \%$ of patients in cohort 1 had a squamous cell carcinoma (48) (Table 1).

These findings demonstrated an anti-tumor effect of vemurafenib in patients with progressive, $B R A F^{V 600 E}$-positive RAI-refractory papillary thyroid cancer who had never been treated with a multikinase inhibitor and who have received vemurafenib as the first line of treatment.

Dabrafenib is a selective and a potent ATP competitive inhibitor of mutated $\mathrm{BRAF}^{\mathrm{V} 600 \mathrm{E}}$ (IC50 $0.5 \mathrm{nM}$ for V600E). A clinical trial with 10 patients with $B R A F^{\mathrm{V} 600 \mathrm{E}}$ mutation, metastatic, or unresectable PTC, who have never been exposed to BRAF or MEK inhibitors, were treated with Dabrafinib, $150 \mathrm{mg}$ twice daily. Fifty percent of participants had cPTC, $40 \%$ had a TC-PTC, and $10 \%$ had a clear cell papillary thyroid cancer. Sixty percent of the patients showed new radioiodine uptake. Six months after radioiodine treatment following dabrafenib, two patients showed a partial response (40 and 60\% reduction of the target lesion) and the remaining four patients had stable disease at 3 months follow-up. The most common adverse effects observed were skin lesions, fatigue, electrolyte abnormalities, and palmar-plantar erythrodysesthesia. However, there was no dose reduction during the study (49) (Table 1). Despite the re-differentiation observed in $60 \%$ of the patients treated with Dabrafenib, these findings suggest that a combination therapy targeting $\mathrm{BRAF}^{\mathrm{V} 600 \mathrm{E}}$ and $\mathrm{MEK}$ would have a greater clinical benefit.

Given the numerous studies supporting the effectiveness of the combination therapy of dabrafenib with the MEK inhibitor trametinib in melanoma, a similar combination therapy was given to patients with undifferentiated thyroid cancer in a multicenter an open-label non-randomized phase II trial (50) (Table 1). Patients with the age of 18 or older, with measurable disease, and with $B R A F^{\mathrm{V} 600 \mathrm{E}}$ mutated tumors were enrolled in the trials. Patients who have been previously treated with BRAF and/or MEK inhibitors were excluded from the study. Combination therapy of dabrafenib and trametinib showed a significant anti-tumor activity and 69\% overall response rate with 1 patient with a complete response. Twelve months duration of response was $90 \%$, PFS was $79 \%$, and OS was $80 \%$. The most common adverse effects of the treatment were fatigue, pyrexia, and nausea. Adverse effects that required discontinuation were reported in $44 \%$ of the patients with ATC. This study demonstrated a great clinical benefit in metastatic undifferentiated thyroid cancer. Dabrafenib and trametinib were approved by the FDA for ATC because of the efficacy in ATC patients with $B R A F^{\mathrm{V} 600 \mathrm{E}}$ mutation.

In a recent open label-multicenter clinical study, patients with advanced thyroid cancer were treated with a combination of trametinib with VEGFR tyrosine kinase inhibitor; pazopanib. Increased level of VEGF and VEGFR1 has been associated with a higher risk of recurrence and the presence of locoregional and distant metastases $(44,59,60)$. Patients enrolled in the study must have a progressive disease, RAI-non avid lesions and a measurable disease to evaluate the response rate. Out of the 13 patients with DTC enrolled in the study, 33\% showed a partial response and $50 \%$ had stable disease. The median follow-up was 37 months. Median progression-free survival and overall survival were 10.7 and 29.3 months. Although trametinib and pazopanib combination therapy showed a high response rate, the lack of a single agent arms does not allow the comparison of the combination therapy vs. single agent (51) (Table 1).

Selumetinib is a potent non-ATP competitive MEK1/2 inhibitor. Selumetinib showed a preferential anti-tumor activity in $B R A F^{\mathrm{V} 600 \mathrm{E}}$ mutated thyroid cancer cell lines $(31,32)$. In an open-label phase II clinical trial including patients with RAIrefractory thyroid cancer with a known tumor genotype and a progressive disease in the last 12 months who have never been exposed to any TKI targeting the MAPK pathway were enrolled. Selumetinib was given at a dose of $100 \mathrm{mg}$ twice daily. Of 32 evaluable patients, only one patient had a partial response and 21 patients had stable disease. Patients with $B R A F^{\mathrm{V} 600 \mathrm{E}}$ tumors had a longer median PFS compared to patients with WT BRAF tumors. These findings were consistent with the preclinical data demonstrating a higher anti-tumor activity of selumetinib in $B R A F^{\mathrm{V} 600 \mathrm{E}}$ mutated cells. The most common adverse effects that were reported are fatigue, diarrhea, and rash. Of 39 enrolled patients, 12 patients had dose reduction and 6 patients discontinued the treatment due to severe adverse effects (52) (Table 1).

Another clinical study of selumetinib was performed in a cohort of 24 patients with metastatic differentiated thyroid cancer treated at a dose of $75 \mathrm{mg}$ twice a day. The endpoints were the refractoriness to RAI and cancer cell redifferentiation. Selumetinib treatment increased the iodine-124 uptake on PETCT in all patients with $N$-RAS mutations (5) and in four out of the nine patients with $B R A F$ mutation. Of all eight patients who qualified for RAI therapy, five patients had a partial response (one patient with $B R A F^{\mathrm{V} 600 \mathrm{E}}$ mutation) and three had stable disease and all showed a reduction of thyroglobulin levels. These results suggest selumetinib is more effective in RAI-refractory thyroid cancer with NRAS mutation compared $B R A F^{\mathrm{V} 600 \mathrm{E}}$ mutated tumors. Selumetinib by inhibiting MAPK pathway re-differentiate thyroid cancer cells and increases iodine uptake (53) (Table 1).

A single-arm multicenter two-stage phase II clinical trial in The United kingdom, aiming at evaluating the efficacy of selumetinib followed by RAI therapy in patients with RAIrefractory thyroid cancer is currently conducted and recruiting patients (61).

\section{Targeting of PI3K/Akt Pathway}

The PI3K/Akt pathway plays a crucial role in thyroid carcinogenesis, cell dedifferentiation, invasion, and metastasis. The three main players of these pathways are PI3K, Akt, and mTOR. Activating mutations and copy gain in the gene coding for the catalytic subunit of PI3K (PIK3CA), and inactivating mutations and hypermethylation of the tumor suppressor gene PTEN have been identified in advanced DTC especially follicular thyroid cancer and ATC. These genetic and epigenetic alterations result in angiogenesis, drug resistance, and thyroid cancer progression and metastasis. The targeting of the $\mathrm{PI} 3 \mathrm{~K} / \mathrm{Akt} / \mathrm{mTOR}$ has been an active area of cancer research. 
Several inhibitors showed promising anti-tumor activity in thyroid cancer cells in vitro and in vivo.

A recent open-label phase II clinical trial evaluated the efficacy of everolimus in RAI-refractory thyroid cancer. Patients of the age of 18 or older with progressive, advanced, or metastatic thyroid cancer who had received up to TKI were enrolled in the study and treated with $10 \mathrm{mg}$ of everolimus daily. Out of the 40 patients with follicular cell-origin thyroid cancer, 35\% had PTC and $17 \%$ had ATC. $72.5 \%$ of patients with follicular cellorigin cancer had a stable disease and only $5 \%$ had a partial response. One of the patients who had a partial response had ATC with PI3K/Akt/mTOR mutations. The results do not allow a correlation between the response to everolimus and the genomic signature of the tumor, mainly because of the small sample size of each genomic group (54) (Table 1).

In another phase II clinical trial assessing the efficacy of everolimus in a cohort of patients with advanced thyroid cancer, everolimus was administered at the dose of $10 \mathrm{mg}$ daily. Sixtyfive percent of patients with differentiated thyroid cancer showed a stable disease as the best response. Forty-six percent of the patients required a dose reduction because of the toxicity of everolimus. Analysis of the somatic mutations in patients' samples did not show any association between mutation status and response to everolimus (55) (Table 1).

These two studies demonstrated the modest anti-tumor activity of everolimus and the stabilization of the disease. However, both trials failed to demonstrate and an association between the mutation status of the tumor and the response to the drug in patients with advanced thyroid cancer.

\section{Anti-angiogenic TKI \\ Sorafenib}

Sorafenib is a multikinase inhibitor that targets VEGFR 1,2 and 3, RET, FLT3, c-Kit, BRAF, and BRAF ${ }^{\mathrm{V} 600 \mathrm{E}}$. It is approved for patients with advanced, iodine-refractory thyroid cancer. Several studies have evaluated the efficacy of sorafenib in advanced thyroid cancer. A phase III placebo-controlled multicenter study assessed the progression-free survival in patients with advanced or metastatic thyroid cancer treated with sorafenib. Patients with age of 18 or older, with advanced or metastatic RAI-refractory thyroid cancer who had progressed in the last 14 months were enrolled. Patients who had received any targeted therapy in the past or chemotherapy were excluded. Sorafenib was given at a daily dose of $800 \mathrm{mg}$. Four hundred and nineteen patients were enrolled in the trial, 207 patients in the sorafenib group and 210 in the placebo group. The median PFS in sorafenib group was significantly longer than that of placebo group (10.8 months for sorafenib group compared to 5.8 months for the placebo group, $p<0.001)$. PFS improvement was observed in all groups irrespective of clinical or demographic features or mutation status. Subgroup analysis showed a significantly longer PFS in patients who had $B R A F^{\mathrm{V} 600 \mathrm{E}}$ and $R A S$ mutated thyroid cancers compared to those with tumors harboring respective mutated genes receiving placebo (20.5 months for $B R A F^{\mathrm{V} 600 \mathrm{E}}$ Sorafenib group vs. 9.4 months $B R A F^{\mathrm{V} 600 \mathrm{E}}$-Placebo group and 5.5 months for mutated RAS-sorafenib group vs. 3.5 months mutated $R A S$-Placebo group). The significantly longer PFS was observed in patients with $B R A F^{\mathrm{WT}}$ and $R A S^{\mathrm{WT}}$ thyroid cancer treated with sorafenib compared to that of patients with tumors harboring respective wild-type genes receiving placebo (8.9 months $B R A F^{\mathrm{WT}}$-sorafenib group vs. 3.8 months for $B R A F^{\mathrm{WT}}$ Placebo group and 10.8 months for wild-type $R A S$-sorafenib group vs. 5.8 months in the wild-type $R A S$-placebo group). Although patients with $B R A F$ mutation showed the longest PFS, neither mutation was predictive of sorafenib response. However, there was no significant difference in the OS between sorafenib and placebo-treated group likely because $71.2 \%$ of patients in the placebo group crossed over to receive sorafenib. $12.2 \%$ of the sorafenib treated patient showed a partial response vs. $0.5 \%$ in the placebo group. Thirty-seven percent of the patients enrolled in the sorafenib group experienced serious adverse events. The most common grade 3 and 4 adverse effects in sorafenib treated group were hand-foot skin reaction, diarrhea, rash or desquamation, and hypertension. One death in the sorafenib group was drugrelated (56) (Table 1). These findings demonstrated a significant improvement of PFS in patients with RAI-refractory thyroid cancer treated with sorafenib. FDA approved sorafenib for the treatment of locally recurrent or metastatic, progressive differentiated, iodine-refractory, thyroid cancer in 2013.

\section{Lenvatinib}

Lenvatinib is a multikinase inhibitor, targeting VEGFR1-3, FGFR, PDGFR, RET, and KIT $(45,62,63)$. An open-label singlearm phase 2 clinical trial was conducted to evaluate the antitumor activity of lenvatinib in advanced thyroid cancer. Fiftyeight patients with RAI-refractory differentiated thyroid cancer who have not received any antiangiogenic targeted therapy in the last 30 days prior to lenvatinib administration were enrolled. Fifty percent of the patients had a partial response, with no significant difference between patients with prior VEGFR- targeted therapy vs. not. Forty-three percent of the patients had stable disease $(\geq 7$ weeks) and $28 \%$ had a durable stable disease ( $\geq 23$ weeks). Most common adverse effects observed were hypertension, weight loss, diarrhea, proteinuria, fatigue nausea, and loss of appetite. Dose interruptions, reduction, and study drug withdrawal occurred in 74,66 , and $26 \%$ of the enrolled patients, respectively. Two patients died from drug-related toxicity (57) (Table 1).

A phase 3 clinical trial with a primary end-point the progression free survival in patients with RAI-refractory progressive thyroid cancer treated with lenvatinib or placebo, demonstrated a significantly longer PFS in patients who received lenvatinib. The median progression survival in the lenvatinib group was 18.3 vs. 3.6 months in the placebo arm. As expected, patients in the lenvatinib group experienced more adverse effects. The most common AEs observed were hypertension, diarrhea, fatigue, and decreased appetite and 6 out of the 20 deaths in the lenvatinib group were drug-related (58) (Table 1). FDA approved lenvatinib for the treatment of advanced, progressive differentiated, iodine-refractory, thyroid cancer in 2013.

\section{Immunotherapy}

The interactions between the tumor microenvironment and cancer cells are involved in cancer progression. The increasing findings regarding the mechanisms underlying the ability of 
cancer cells to escape the immune response surveillance have made the immune system a new promising therapeutic target in oncology.

Analysis of the Immunoscore, a method to estimate the prognosis of patients with cancer based on the infiltrative immune cells in cancer, of 505 patients with thyroid cancer, revealed a significant negative correlation between thyroid differentiation score and immunosuppressive markers such as CTLA-4 and PD-L1. These immunosuppressive markers were significantly higher in $B R A F^{\mathrm{V} 600 \mathrm{E}}$-mutated tumors compared to wild-type tumors (64). Increased PD-L1 expression has been demonstrated in several solid tumors and has been associated with poor prognosis $(65,66)$. Tumors cells harboring PD-L1 expression inhibits $\mathrm{T}$ cell activation in the tumor microenvironment thus protecting tumors cells from the immune response. Analysis of the prognostic potential of PDL1 in 185 PTC and 66 benign nodules, showed that increased expression of PD-L1 in thyroid cancer is associated with a higher risk of recurrence and shorter DFS (67). These findings suggest that the targeting of PD-L1 could be an effective therapy in advanced thyroid cancer.

In a phase $\mathrm{Ib}$ clinical trial assessing the safety and the antitumor activity of the anti-PD-1 antibody pembrolizumab, 22 patients with locally advanced or metastatic differentiated thyroid cancer, positive for PD-L1 expression, who have never received anti-cancer monoclonal antibody therapy in the last 4 weeks before treatment, or targeted therapy in the last 2 weeks prior the treatment. Patients participating in the trial received $10 \mathrm{mg} / \mathrm{kg}$ of pembrolizumab every 2 weeks for 24 months. Two patients with PTC had a PR after 4 and 5 months of treatment, and response duration of 20 and 8 months. Fifty-seven percent of the patients with FTC and $60 \%$ of patients with PTC had a stable disease with a median duration of 7 months. PFS rate at 6 and 12 months were 59 and 36\%, respectively (68). These

\section{REFERENCES}

1. Haugen BR, Alexander EK, Bible KC, Doherty GM, Mandel SJ, Nikiforov YE, et al. 2015 American Thyroid Association Management Guidelines for adult patients with thyroid nodules and differentiated thyroid cancer: the American Thyroid Association Guidelines task force on thyroid nodules and differentiated thyroid cancer. Thyroid. (2016) 26:1-133. doi: 10.1089/thy.2015.0020

2. Ghossein RA, Leboeuf R, Patel KN, Rivera M, Katabi N, Carlson DL, et al. Tall cell variant of papillary thyroid carcinoma without extrathyroid extension: biologic behavior and clinical implications. Thyroid. (2007) 17:65561. doi: 10.1089/thy.2007.0061

3. Silver CE, Owen RP, Rodrigo JP, Rinaldo A, Devaney KO, Ferlito A. Aggressive variants of papillary thyroid carcinoma. Head Neck. (2011) 33:1052-9. doi: $10.1002 /$ hed.21494

4. Poller DN, Nikiforov YE. Non-invasive follicular thyroid neoplasm with papillary-like nuclei: reducing overtreatment by reclassifying an indolent variant of papillary thyroid cancer. J Clin Pathol. (2016) 69. doi: 10.1136/jclinpath-2016-203930

5. Nikiforov YE, Erickson LA, Nikiforova MN, Caudill CM, Lloyd RV. Solid variant of papillary thyroid carcinoma: incidence, clinical-pathologic characteristics, molecular analysis, and biologic behavior. Am J Surg Pathol. (2001) 25:1478-84. doi: 10.1097/00000478-200112000-00002 observations showing a clinical benefit of pembrolizumab suggest that targeting PD-1 is a good therapeutic strategy for advanced thyroid cancer.

In addition, a combination of PLX4720, a $B R A F^{\mathrm{V} 600 \mathrm{E}}$ inhibitor and anti-PD-L1/PD-1 antibody in a preclinical model of ATC, reduced the tumor growth, and increased in tumor $\mathrm{CD}^{+}$cytotoxic $\mathrm{T}$ cells, FoxP3 ${ }^{+}$Tregs, and NK cells, thus demonstrating an induction of the immunosuppressive tumor microenvironment. Taken together, these findings suggest that a combination therapy of BRAF ${ }^{\mathrm{V} 600 \mathrm{E}}$ inhibitor and anti- PD-1/PDL1 antibody is a promising therapeutic strategy for metastatic thyroid cancer.

\section{CONCLUSIONS}

The treatment of advanced and metastatic iodine-refractory thyroid cancer remains very challenging. Recent discoveries in the molecular pathogenesis of thyroid cancer have led to major advances in the treatment and management of aggressive tumors. Preclinical and clinical studies with targeted therapies and immune therapies have demonstrated a significant clinical benefit. Further studies are needed to improve these therapeutic strategies to offer a better treatment for patients with advanced and metastatic thyroid cancer.

\section{AUTHOR CONTRIBUTIONS}

All authors have contributed to the preparation of this manuscript. All authors have read and approved the manuscript.

\section{ACKNOWLEDGMENTS}

The preparation of this manuscript was supported by the NIH intramural research grant (\#ZIA BC 011286).
6. McHenry CR, Phitayakorn R. Follicular adenoma and carcinoma of the thyroid gland. Oncologist. (2011) 16:585-93. doi: 10.1634/theoncologist.2010-0405

7. Howell GM, Hodak SP, Yip L. RAS mutations in thyroid cancer. Oncologist. (2013) 18:926-32. doi: 10.1634/theoncologist.2013-0072

8. Nikiforova MN, Lynch RA, Biddinger PW, Alexander EK, Dorn GW, Tallini $\mathrm{G}$, et al. RAS point mutations and PAX8-PPAR gamma rearrangement in thyroid tumors: evidence for distinct molecular pathways in thyroid follicular carcinoma. J Clin Endocrinol Metab. (2003) 88:2318-26. doi: 10.1210/jc.2002-021907

9. Wu G, Mambo Z, Guo S, Hu X, Huang SM, Gollin et al. Uncommon mutation, but common amplifications, of the PIK3CA gene in thyroid tumors. J Clin Endocrinol Metab. (2005) 90:4688-93. doi: 10.1210/jc.2004-2281

10. Liu Z, Hou P, Ji M, Guan H, Studeman K, Jensen K, et al. Highly prevalent genetic alterations in receptor tyrosine kinases and phosphatidylinositol 3-kinase/akt and mitogen-activated protein kinase pathways in anaplastic and follicular thyroid cancers. J Clin Endocrinol Metab. (2008) 93:3106-16. doi: 10.1210/jc.2008-0273

11. Hou P, Ji M, Xing M. Association of PTEN gene methylation with genetic alterations in the phosphatidylinositol 3-kinase/AKT signaling pathway in thyroid tumors. Cancer. (2008) 113:2440-7. doi: 10.1002/cncr.23869

12. Volante M, Landolfi S, Chiusa L, Palestini N, Motta M, Codegone A, et al. Poorly differentiated carcinomas of the thyroid with trabecular, insular, 
and solid patterns: a clinicopathologic study of 183 patients. Cancer. (2004) 100:950-7. doi: 10.1002/cncr.20087

13. Hiltzik D, Carlson DL, Tuttle RM, Chuai S, Ishill N, Shaha A, et al. Poorly differentiated thyroid carcinomas defined on the basis of mitosis and necrosis: a clinicopathologic study of 58 patients. Cancer. (2006) 106:1286-95. doi: $10.1002 / \mathrm{cncr} .21739$

14. Jung CK, Little MP, Lubin JH, Brenner AV, Wells SA, Sigurdson AJ, et al. The increase in thyroid cancer incidence during the last four decades is accompanied by a high frequency of BRAF mutations and a sharp increase in RAS mutations. J Clin Endocrinol Metab. (2014) 99:E276-85. doi: 10.1210/jc.2013-2503

15. Landa I, Ibrahimpasic T, Boucai L, Sinha R, Knauf JA, Shah RH, et al. Genomic and transcriptomic hallmarks of poorly differentiated and anaplastic thyroid cancers. J Clin Invest. (2016) 126:1052-66. doi: 10.1172/JCI85271

16. Donghi R, Longoni A, Pilotti S, Michieli P, Della Porta G, Pierotti MA. Gene p53 mutations are restricted to poorly differentiated and undifferentiated carcinomas of the thyroid gland. J Clin Invest. (1993) 91:1753-60. doi: 10.1172/JCI116385

17. Garcia-Rostan G, Camp RL, Herrero A, Carcangiu ML, Rimm DL, Tallini G. Beta-catenin dysregulation in thyroid neoplasms: down-regulation, aberrant nuclear expression, and CTNNB1 exon 3 mutations are markers for aggressive tumor phenotypes and poor prognosis. Am J Pathol. (2001) 158:987-96. doi: 10.1016/S0002-9440(10)64045-X

18. Smallridge RC, Copland JA. Anaplastic thyroid carcinoma: pathogenesis and emerging therapies. Clin Oncol. (2010) 22:486-97. doi: $10.1016 /$ j.clon.2010.03.013

19. Wendler J, Kroiss M, Gast K, Kreissl MC, Allelein S, Lichtenauer U, et al. Clinical presentation, treatment and outcome of anaplastic thyroid carcinoma: results of a multicenter study in Germany. Eur J Endocrinol. (2016) 175:521-9. doi: 10.1530/EJE-16-0574

20. Lim H, Devesa SS, Sosa JA, Check D, Kitahara CM. Trends in thyroid cancer incidence and mortality in the United States, 1974-2013. JAMA. (2017) 317:1338-48. doi: 10.1001/jama.2017.2719

21. Nel CJ, van Heerden JA, Goellner JR, Gharib H, McConahey WM, Taylor WF, et al. Anaplastic carcinoma of the thyroid: a clinicopathologic study of 82 cases. Mayo Clin Proc. (1985) 60:51-8. doi: 10.1016/S0025-6196(12)65285-9

22. Bonhomme B, Godbert Y, Perot G, Al Ghuzlan A, Bardet S, Belleannée G, et al. Molecular Pathology of Anaplastic Thyroid Carcinomas: A Retrospective Study of 144 Cases. Thyroid. (2017) 27:682-92. doi: 10.1089/thy.2016.0254

23. Schmidbauer B, Menhart K, Hellwig D, Grosse J. Differentiated thyroid cancer-treatment: state of the art. Int J Mol Sci. (2017) 18:E1292. doi: $10.3390 /$ ijms 18061292

24. McDougall IR, Weigel RJ. Recombinant human thyrotropin in the management of thyroid cancer. Curr Opin Oncol. (2001) 13:39-43. doi: 10.1097/00001622-200101000-00008

25. Brabant G. Thyroid gland malfunction. MMW Fortschr Med. (2004) 146:302,34 .

26. Cooper DS, Specker B, Ho M, Sperling M, Ladenson PW, Ross DS, et al. Thyrotropin suppression and disease progression in patients with differentiated thyroid cancer: results from the National Thyroid Cancer Treatment Cooperative Registry. Thyroid. (1998) 8:737-44. doi: 10.1089/thy.1998.8.737

27. Biondi B, Cooper DS. Benefits of thyrotropin suppression versus the risks of adverse effects in differentiated thyroid cancer. Thyroid. (2010) 20:135-46. doi: $10.1089 /$ thy.2009.0311

28. Haugen BR. 2015 American Thyroid Association Management Guidelines for Adult Patients with Thyroid Nodules and Differentiated Thyroid Cancer: What is new and what has changed? Cancer. (2017) 123:372-81. doi: $10.1002 /$ cncr. 30360

29. Mercer KE, Pritchard CA. Raf proteins and cancer: B-Raf is identified as a mutational target. Biochim Biophys Acta. (2003) 1653:25-40. doi: 10.1016/S0304-419X(03)00016-7

30. Salerno P, De Falco V, Tamburrino A, Nappi TC, Vecchio G, Schweppe RE, et al. Cytostatic activity of adenosine triphosphate-competitive kinase inhibitors in BRAF mutant thyroid carcinoma cells. J Clin Endocrinol Metab. (2010) 95:450-5. doi: 10.1210/jc.2009-0373

31. Ball DW, Jin N, Rosen DM, Dackiw A, Sidransky D, Xing M, et al. Selective growth inhibition in BRAF mutant thyroid cancer by the mitogen-activated protein kinase kinase 1/2 inhibitor AZD(6244) J Clin Endocrinol Metab. (2007) 92:4712-8. doi: 10.1210/jc.2007-1184

32. Leboeuf R, Baumgartner JE, Benezra M, Malaguarnera R, Solit D, Pratilas $\mathrm{CA}$, et al. BRAFV600E mutation is associated with preferential sensitivity to mitogen-activated protein kinase kinase inhibition in thyroid cancer cell lines. J Clin Endocrinol Metab. (2008) 93:2194-201. doi: 10.1210/jc.2007-2825

33. Vitale G, Dicitore A, Pepe D, Gentilini D, Grassi ES, Borghi MO, et al. Synergistic activity of everolimus and 5-aza-2'-deoxycytidine in medullary thyroid carcinoma cell lines. Mol Oncol. (2017) 11:1007-22. doi: $10.1002 / 1878-0261.12070$

34. Hanly EK, Bednarczyk RB, Tuli NY, Moscatello AL, Halicka HD, Li J, et al. mTOR inhibitors sensitize thyroid cancer cells to cytotoxic effect of vemurafenib. Oncotarget. (2015) 6:39702-13. doi: 10.18632/oncotarg et. 4052

35. Sadowski SM, Boufraqech M, Zhang L, Mehta A, Kapur P, Zhang Y, et al. Torin2 targets dysregulated pathways in anaplastic thyroid cancer and inhibits tumor growth and metastasis. Oncotarget. (2015) 6:18038-49. doi: 10.18632/oncotarget.3833

36. Yamamoto Y, Matsui J, Matsushima T, Obaishi H, Miyazaki K, Nakamura $\mathrm{K}$, et al. Lenvatinib, an angiogenesis inhibitor targeting VEGFR/FGFR, shows broad antitumor activity in human tumor xenograft models associated with microvessel density and pericyte coverage. Vasc Cell. (2014) 6:18. doi: $10.1186 / 2045-824 X-6-18$

37. Brauner E, Gunda V, Vanden Borre P, Zurakowski D, Kim YS, Dennett $\mathrm{KV}$, et al. Combining BRAF inhibitor and anti PD-L1 antibody dramatically improves tumor regression and anti tumor immunity in an immunocompetent murine model of anaplastic thyroid cancer. Oncotarget. (2016) 7:17194-211. doi: 10.18632/oncotarget.7839

38. Gunda V, Gigliotti B, Ashry T, Ndishabandi D, McCarthy M, Zhou Z, et al. Anti-PD-1/PD-L1 therapy augments lenvatinib's efficacy by favorably altering the immune microenvironment of murine anaplastic thyroid cancer. Int $J$ Cancer. (2019) 144:2266-78. doi: 10.1002/ijc.32041

39. Cantara S, Bertelli E, Occhini R, Regoli M, Brilli L, Pacini F, et al. Blockade of the programmed death ligand 1 (PD-L1) as potential therapy for anaplastic thyroid cancer. Endocrine. (2019) 64:122-9. doi: 10.1007/s12020-019-01865-5

40. Hutton JE, Wang X, Zimmerman LJ, Slebos RJ, Trenary IA, Young JD, et al. Oncogenic KRAS and BRAF drive metabolic reprogramming in colorectal cancer. Mol Cell Proteomics. (2016) 15:2924-38. doi: 10.1074/mcp.M116.058925

41. Xing M. Molecular pathogenesis and mechanisms of thyroid cancer. Nat Rev Cancer. (2013) 13:184-99. doi: 10.1038/nrc3431

42. Kimura ET, Nikiforova MN, Zhu Z, Knauf JA, Nikiforov YE, Fagin JA. High prevalence of BRAF mutations in thyroid cancer: genetic evidence for constitutive activation of the RET/PTC-RAS-BRAF signaling pathway in papillary thyroid carcinoma. Cancer Res. (2003) 63:1454-7. doi: 10.3410/f.717987086.793472329

43. Soares P, Trovisco V, Rocha AS, Lima J, Castro P, Preto A, et al. BRAF mutations and RET/PTC rearrangements are alternative events in the etiopathogenesis of PT. Oncogene C. (2003) 22:4578-80. doi: 10.1038/sj.onc. 1206706

44. Ferrari SM, Fallahi P, Politti U, Materazzi G, Baldini E, Ulisse S, et al. Molecular targeted therapies of aggressive thyroid cancer. Front Endocrinol. (2015) 6:176. doi: $10.3389 /$ fendo. 2015.00176

45. Fallahi P, Ruffilli I, Elia G, Ragusa F, Ulisse S, Baldini E, et al. Novel treatment options for anaplastic thyroid cancer. Expert Rev Endocrinol Metab. (2017) 12:279-288. doi: 10.1080/17446651.2017.1340155

46. Bollag G, Hirth P, Tsai J, Zhang J, Ibrahim PN, Cho H, et al. Clinical efficacy of a RAF inhibitor needs broad target blockade in BRAF-mutant melanoma. Nature. (2010) 467:596-9. doi: 10.1038/nature09454

47. Kim KB, Cabanillas ME, Lazar AJ, Williams MD, Sanders DL, Ilagan JL, et al. Clinical responses to vemurafenib in patients with metastatic papillary thyroid cancer harboring BRAF(V600E) mutation. Thyroid. (2013) 23:127783. doi: 10.1089/thy.2013.0057

48. Brose MS, Cabanillas ME, Cohen EE, Wirth LJ, Riehl T, Yue H, et al. Vemurafenib in patients with $\mathrm{BRAF}(\mathrm{V} 600 \mathrm{E})$-positive metastatic or unresectable papillary thyroid cancer refractory to radioactive iodine: a nonrandomised, multicentre, open-label, phase 2 trial. Lancet Oncol. (2016) 17:1272-82. doi: 10.1016/S1470-2045(16)30166-8 
49. Rothenberg SM, McFadden DG, Palmer EL, Daniels GH, Wirth LJ. Redifferentiation of iodine-refractory BRAF V600E-mutant metastatic papillary thyroid cancer with dabrafenib. Clin Cancer Res. (2015) 21:1028-35. doi: 10.1158/1078-0432.CCR-14-2915

50. Subbiah V, Kreitman RJ, Wainberg ZA, Cho JY, Schellens JHM, Soria JC, et al. Dabrafenib and trametinib treatment in patients with locally advanced or metastatic BRAF V600-mutant anaplastic thyroid cancer. J Clin Oncol. (2018) 36:7-13. doi: 10.1200/JCO.2017.73.6785

51. Kurzrock R, Ball DW, Zahurak ML, Nelkin BD, Subbiah V, Ahmed S, et al. A Phase I Trial of the VEGF receptor tyrosine kinase inhibitor pazopanib in combination with the MEK inhibitor trametinib in advanced solid tumors and differentiated thyroid cancers. Clin Cancer Res. (2019) 25. doi: 10.1158/1078-0432.CCR-18-1881

52. Hayes DN, Lucas AS, Tanvetyanon T, Krzyzanowska MK, Chung CH, Murphy BA, et al. Phase II efficacy and pharmacogenomic study of Selumetinib (AZD6244; ARRY-142886) in iodine-131 refractory papillary thyroid carcinoma with or without follicular elements. Clin Cancer Res. (2012) 18:2056-65. doi: 10.1158/1078-0432.CCR-11-0563

53. Ho AL, Grewal RK, Leboeuf R, Sherman EJ, Pfister DG, Deandreis D, et al. Selumetinib-enhanced radioiodine uptake in advanced thyroid cancer. N Engl J Med. (2013) 368:623-32. doi: 10.1056/NEJMoa1209288

54. Hanna GJ, Busaidy NL, Chau NG, Wirth LJ, Barletta JA, Calles A, et al. Genomic correlates of response to everolimus in aggressive radioiodinerefractory thyroid cancer: a phase II study. Clin Cancer Res. (2018) 24:154653. doi: 10.1158/1078-0432.CCR-17-2297

55. Schneider TC, de Wit D, Links TP, van Erp NP, van der Hoeven JJ, Gelderblom $\mathrm{H}$, Everolimus in Patients With Advanced Follicular-Derived Thyroid Cancer: Results of a Phase II Clinical Trial. J Clin Endocrinol Metab. (2017) 102:698707. doi: 10.1210/jc.2017-00661

56. Brose MS, Nutting CM, Jarzab B, Elisei R, Siena S, Bastholt L, et al. Sorafenib in radioactive iodine-refractory, locally advanced or metastatic differentiated thyroid cancer: a randomised, double-blind, phase 3 trial. Lancet. (2014) 384:319-28. doi: 10.1016/S0140-6736(14)60421-9

57. Cabanillas ME, Schlumberger M, Jarzab B, Martins RG, Pacini F, Robinson $\mathrm{B}$, et al. A phase 2 trial of lenvatinib (E7080) in advanced, progressive, radioiodine-refractory, differentiated thyroid cancer: A clinical outcomes and biomarker assessment. Cancer. (2015) 121:2749-56. doi: 10.1002/cncr.29395

58. Schlumberger M, Tahara M, Wirth LJ, Robinson B, Brose MS, Elisei R, et al. Lenvatinib versus placebo in radioiodine-refractory thyroid cancer. $N$ Engl $J$ Med. (2015) 372:621-30. doi: 10.1056/NEJMoa1406470

59. Vieira JM, Santos SC, Espadinha C, Correia I, Vag T, Casalou C, et al. Expression of vascular endothelial growth factor (VEGF) and its receptors in thyroid carcinomas of follicular origin: a potential autocrine loop. Eur $J$ Endocrinol. (2005) 153:701-9. doi: 10.1530/eje.1.02009

60. Karaca Z, Tanriverdi F, Unluhizarci K, Ozturk F, Gokahmetoglu S, Elbuken $\mathrm{G}$, et al. VEGFR1 expression is related to lymph node metastasis and serum VEGF may be a marker of progression in the follow-up of patients with differentiated thyroid carcinoma. Eur J Endocrinol. (2011) 164:277-84 doi: 10.1530/EJE-10-0967

61. Brown SR, Hall A, Buckley HL, Flanagan L, Gonzalez de Castro D, Farnell K, et al. Investigating the potential clinical benefit of Selumetinib in resensitising advanced iodine refractory differentiated thyroid cancer to radioiodine therapy (SEL-I-METRY): protocol for a multicentre UK single arm phase II trial. BMC Cancer. (2019) 19:582. doi: 10.1186/s12885-0195541-4

62. Matsui J, Yamamoto Y, Funahashi Y, Tsuruoka A, Watanabe T, Wakabayashi $\mathrm{T}$, et al. E7080, a novel inhibitor that targets multiple kinases, has potent antitumor activities against stem cell factor producing human small cell lung cancer H146, based on angiogenesis inhibition. Int J Cancer. (2008) 122:664-71. doi: 10.1002/ijc.23131

63. Okamoto K, Kodama K, Takase K, Sugi NH, Yamamoto Y, Iwata M, et al. Antitumor activities of the targeted multi-tyrosine kinase inhibitor lenvatinib (E7080) against RET gene fusion-driven tumor models. Cancer Lett. (2013) 340:97-103. doi: 10.1016/j.canlet.2013.07.007

64. Na KJ, Choi H. Immune landscape of papillary thyroid cancer and immunotherapeutic implications. Endocr Relat Cancer. (2018) 25:523-31. doi: 10.1530/ERC-17-0532

65. Ohigashi Y, Sho M, Yamada Y, Tsurui Y, Hamada K, Ikeda N, et al. Clinical significance of programmed death-1 ligand-1 and programmed death-1 ligand-2 expression in human esophageal cancer. Clin Cancer Res. (2005) 11:2947-53. doi: 10.1158/1078-0432.CCR-04-1469

66. Lin YM, Sung WW, Hsieh MJ, Tsai SC, Lai HW, Yang SM, et al. High PD-L1 Expression Correlates with Metastasis and Poor Prognosis in Oral Squamous Cell Carcinoma. PLoS ONE. (2015) 10:e0142656. doi: 10.1371/journal.pone.0142656

67. Massari F, Santoni M, Ciccarese C, Santini D, Alfieri S, Martignoni G, et al. PD-1 blockade therapy in renal cell carcinoma: current studies and future promises. Cancer Treat Rev. (2015) 41:114-21. doi: 10.1016/j.ctrv.2014.12.013

68. Mehnert JM, Varga A, Brose MS, Aggarwal RR, Lin CC, Prawira A, et al Safety and antitumor activity of the anti-PD-1 antibody pembrolizumab in patients with advanced, PD-L1-positive papillary or follicular thyroid cancer. BMC Cancer. (2019) 19:196. doi: 10.1186/s12885-019-5380-3

Conflict of Interest: The authors declare that the research was conducted in the absence of any commercial or financial relationships that could be construed as a potential conflict of interest.

Copyright (c) 2020 Laha, Nilubol and Boufraqech. This is an open-access article distributed under the terms of the Creative Commons Attribution License (CC BY). The use, distribution or reproduction in other forums is permitted, provided the original author(s) and the copyright owner(s) are credited and that the original publication in this journal is cited, in accordance with accepted academic practice. No use, distribution or reproduction is permitted which does not comply with these terms. 